\title{
最近の上方向への影響戦略に関する研究の動向 一社会的相互作用の視点から一
}

\author{
㴊 上 克 義 \\ 鹿児島大学
}

Research trends on recent upward influence strategies

from the view points of social interactional analysis

Fuchigami Katsuyoshi (Kagoshima University)

\section{I. はじめに}

最近のリーダーシップや社会的パワーなどの社会的影響 過程に関する研究の顕著な動向の一つに, 階層構造内で下 位者（地位の低い者）が現実にどのようにして上位者（自 分より高い地位を占めている者）に働きかけながら, 影響 を及ほしていくのかという研究領域がある (Bass, 1990： Kipnis, 1990: Lord \& Maher, 1991: Yukl, 1989)。この 研究は上方向への影響戦略 (Upward Influence Strategy) と呼ばれ, 1980 年代から数多くの実証的な研究が行われ るようになってきた。一般に上方向への影響戦略とは「集 団・組織の階層構造内で自分より上位を占めている者に 対して用いられる意図的な影響手段」(Mayers \& Allen, 1977：Droy \& Romm, 1990）と定義される。

\section{1. 上方向への影響戦略研究の動向と本研究の目的}

もともと階層構造内での下位者から上位者への上方向 コミュニケーションの特徵に関しては, 社会心理学の分 野でも以前から検討されてきた (Cohen, 1958：Kelly, 1951)。

また集団・組織内での意思決定や有効性に上方向への 影響力が重要なことも知られていた (Pelz, 1951)。それ によれば，フォロワーの目標遂行を推進するミドルリー ダー行動は，彼が組織内での上方向への強い影響力を持っ
ている場合にのみ, フォロワーの満足度と正の相関を持 つことが明らかにされている。つまり目標遂行に関する ミドルリーダー行動の有効性を媒介するものとして, 彼 らの上方向への影響力の重要性を指摘している。

これは後に Pelz 効果と呼ばれ，社会心理学や組織心 理学のテキストに引用されてきた。このように上方向へ の影響力の重要性は以前から指摘されていたにも関わら ず，その後リーダーシップや社会的パワーに関する研究 は上位者から下位者への一方向的で下方向への影響過程

(Downward Influence Process) にのみ集中した。とこ ろが上方向への影響戦略に関わる実証的研究が行われる ようになった最近になって, 再び Pelz 効果の有効性が 注目されている (Anderson, Tolson, Fields \& Thacker, 1990: Anderson \& Tolson, 1991: 金井, 1991)。

ではなぜ 1980 年代になって, 上方向への影響戦略研究 が行われるようになったのか。まず第一に現実現場での影 響戦略が注目されるようになってきた。これまで社会的影 響力の拠り所である社会的パワーに関しては, French \& Raven（1959）の五つのパワーの分類がよく知られてい た。そして最近この社会的パワーの分類については測定 法を厳密にしたり, 実証的な研究に基づいた研究が行わ れるようになった (Hinkin \& Schriesheim, 1989: 今井, 1992: Rahim, 1988: Schriesheim, Hinkin \& Podsakoff 
1990)

さらにそのような分類だけでなく, 社会的パワーが実 際の集団や組織でどのように用いられているのか, つま り現実場面で他者を動かす影響戦略への関心が高まって きた。もともと影響戦略の中でも上位者の報酬行動と罰行 動の効果は以前から詳細に検討されてきたものの（Sims, 1977: Podsakoff, 1982) , 最近, より幅広い影響戦略に 関する実証的研究が行われるようになってきた（Kipnis, Schmidt \& Wilkinson, 1980: Schriensheim \& Hinkin, 1990：Yukl \& Falbe, 1990）。そこでは階層構造内での 上位者から下位者に対する下への影響戦略だけでなく, 公 的・私的目的遂行のために下位者から上位者へより積極的 に働きかけるという意味での影響戦略も注目されるよう になった。さらに階層構造内での印象操作（上位者を印 象操作によって動かす）に関する研究は一定の裁量権を 持つミドルリーダーだけでなく，より下位者による上方 向への影響戦略に関する研究を盛り上げた（Blase, 1989: Giacalone \& Rosen feld, 1989: Tedeschi \& Melburge, 1984: Ralston, 1985: Liden \& Mitchell, 1988)。

次に上方向への影響戦略研究が行われるようになった 第二の理由は, 社会的影響過程の研究において相互作用プ ロセスが注目されてきた点である。これまで階層構造内で のリーダーシップを中心とした社会的影響過程の研究は, その多くが上位者から下位者への一方向的で下方向への 影響過程に限定されてきた（Bass, 1990：Yukl, 1989）。 そこでは上位者の影響に下位者は黙って従うことが暗黙 の前提であった。

ところが 1970 年代後半から 1980 年代になって, 上位 者の下位者個々への影響力の質の違い（Grean, 1976）や 下位者の反応（行動）によって上位者のとる行動が異な ること（Mitchell, Green \& Wood, 1981）が明らかにな ると, 社会的影響過程を上位者と下位者の認知も含めた 両者の相互作用プロセスとして捉えるようになってきた （古川, 1991：Lord \& Maher, 1991）。この見方によれ ば, 上位者は最終的な意思決定権を持つものの, それに 至るまでに様々な相互作用を行う。そして彼らはそのま ま自分の意見を変えない場合もあるが，時には大きく意 見を修正したり，場合によっては自分の意見を撤回する ことさえある。そこでは上から下への影響過程だけでな く, 情報・知識やスキルなどを中心とした下位者への依 存性をもとにした下から上への影響過程も過小評価でき ない（金井, 1991)。

したがって，上位者が何らかの意思決定を行うまでに， 下位者も彼らに対して一定程度の影響力を持ちうること になる。そこでは下位者が単に上位者の行動を解釈し, 反
応するだけでなく，どのようにして積極的に働きかけるの かという上方向への影響戦略が注目されるようになった。

上方向への影響戦略研究が注目されるようになった第 三点は, 組織政策 (Organizational Politics) 研究の登場 である。1970 年代後半から 80 年代にかけて組織の合理性 モデルに対する批判として, 組織政策に関する研究が行 われるようになった（Mayers \& Allen, 1977: Madison, Allen, Porter, Renweik \& Mayers, 1980: Bacharach \& Lawler, 1980: Vredenburgh \& Maurer, 1984）。さらに 企業組織だけでなく, 教育組織においても組織政策に注 目するようになってきた（Hoyle, 1986: Blase, 1991）。

そこでは組織を，(1)様々な異なる利益を持つ下位集団 の複合体として捉え，(2)自集団の利益のために様々な働 きかけを行い，(3)ある時は協同し，またある時は競争す るという政治的な駆け引きの場として捉える (Mayers \& Allen, 1977: Madison et al, 1980: Bacharach \& Lawler, 1980: Blase, 1992) 。したがってそこでは上位 者から下位者への下方向への統制的な影響過程（例えば 上司から部下へ，校長から教師へなど）だけでなく，下 位集団間の勢力関係（部下集団や教師集団同士の相互影 響過程など）や下位者から上位者への影響過程（部下か ら上司へ, 教師から校長へなど）の解明を通して, 組織 全体をとしての活動をどのように統合・調整するかが極 めて重要になってくる。

さて以上のような研究動向を踏まえながら，本研究は 上位者と下位者の相互作用の視点から先行研究を整理し ながら，新しい展開を試みようとするものである。

第一に,これまで行われてきた上方向への影響戦略に 関する実証的な研究成果を大きく三つに分類して整理す る。まず現実にどのような影響戦略が用いられているの か影響戦略の内容に関する研究。次に実際に下位者が数 ある影響戦略の中から一つを選択し，上位者へ働きかけ る行動に注目した研究をみていく。そこでは影響戦略の 選択や実際の行動を規定する要因を整理する。最後にこ のような影響戦略が上位者や集団全体もしくは自分自身 にいかなる影響を及ぼすのかを検討する。

第二にそれぞれの領域で明らかにされた研究成果を踏 まえながら，何がわかったのかを仮説の形で提示する。そ して最後に今後の問題点及びこれからの研究展望を行う。

\section{II. 上方向への影響戦略の内容に関する研究}

上方向への影響戦略に関する実証的な研究が始まった 頃は, 下位者の影響戦略に関する自由記述の分類が試みら れていた (Madison et al, 1980: Mowday, 1978: Shilit 
\& Locke, 1982)。

その後影響戦略についての自由記述の単なる分類だけで なく, Kipnis et al, (1980) は因子分析によって影響戦略 の内容を明らかにしょうとした。彼らはまず管理者を対象 に影響戦略の自由記述 (どのような方法で自分の意図通り に相手を上手に動かそうとするのか) を14 のカテゴリー に分類して，同一の管理者を対象にして因子分析を行っ た。その結果以下の八つの影響戦略が見い出だされた。 (1)合理性（理由や根拠をきちんと説明するなど），(2)迎 合性（へりくだる，ご機嫌をとるなど），(3)主張性（はっ きりと要求する，自分の意見のみを強く述べるなど）, (†)交換性（相手の意見を認める代わりに，別の機会に自 分の意見を認めてもらうなど），(5)結託性（同嘹を味方 につけるなど），(6より高い権威性（自分の直接の上司 より地位の高い人の支持をとりつけるなど），(7制裁性 （会社を辞めるなどといって勗すなど），8遮断性（仕 事のペースを落とすなど）。その後 Kipnis et al (1980) は, 実際の使用頻度の少ないものや上方向への影響戦略 として不適切として,(つと(8の影響戦略を除いた六つの 影響戦略を整理して, 組織の影響戦略の質問紙 (Profile of Organizational Influence Strategy) を作成した。

さて彼らの見い出だした影響戦略は後の研究に大きな影 響を与えた。その後の上方向への影響戦略研究の多くは, 彼らの質問紙をそのまま用いて組織内での影響戦略の機 能を検討したものが多い。またそうでない場合も彼らの影 響戦略の項目を基にして因子分析を行っている (Ansari \& Kapoor, 1986: Erez, Rim \& Keider, 1986)。

さらに最近，質問項目の再検討も行われている (Kumar \& Beyerle in, 1991: Schriesheim \& Hinkin, 1990: Yukl \& Falbe, 1990)。それによれば, 各影響戦略を 測定するいくつかの下意項目の内容妥当性への疑問や (Schriesheim \& Hinkin, 1990)，新たな影響戦略の追 加（情熱性, 相談性）の必要性 (Yuk1 \& Falbe, 1990) な どが指摘されているものの, 六つの影響戦略の存在は確認 されている。また影響戦略の中でも迎合性を取り上げて, より精緻な質問紙の作成を試みた研究もある。(Kumar \& Beyerlein, 1991)。

以上のように, 上方向への影響戦略として他に一, 二 の影響戦略がみられるものの, 基本的には六つの種類が あるといえよう。

仮説 1 . 下位者は合理性, 迎合性, 主張性, 交換性, 結託性, より高い権威性の六つの影響戦略を用いながら, 上位者へ働きかけるだろう。

\section{III. 下位者の影響戦略選択の規定因に関する研究}

ここでは，下位者が一つの影響戦略の使用を決定する までにいかなる要因が影響を及ぼしているのかを整理す る。まず彼らの影響戦略行動の基本的特徴を明らかにす る。次に影響戦略行動を規定する要因として, 下位者自 身の個人的特徵, 上位者との関係, 下位者の持つ目標, 状 況的要因について概観する。

\section{1. 下位者の行動特徵}

一般に下位者は上位者に対して, 丁寧で間接的な影 響戦略を用いることが知られている (Steffen \& Eagly, 1985）。下位者の影響戦略に関連した研究は, 彼らの各 影響戦略の頻度を比較したり, 組織内での上方向・水平 方向・下方向への影響戦略の比較検討をすることによっ て, 彼らの影響戦略の基本的な特徵を明らかにしようと したものが多い。

それらの研究結果によれば, 合理性は最も高い頻度で用 いられ, 迎合性は中程度, 主張性やより高い権威性の頻度 は低いことが一貫して見い出されている（Barnett, 1984 : Blase, 1987: Chacko, 1990: Deluga, 1988a: Erez, Rim \& Keider, 1986: 㴊上, 1992a: Kipnis et al, 1980: Mowday, 1978: Shilit \& Locke, 1982: Schriesheim \& Hinkin, 1990：Yukl \& Falbe, 1990）。下位者は上位者 に比へて地位に伴う影響力を多く持たないので，地位に 伴う影響力を用いたり，自分を強く主張することができ ないためと思われる。

ところが下位者による交換性と結託性の使用頻度につ いては, 高い結果と低い結果が見い出されており必ずし も一貫していない。例えば企業組織を対象とした Kipnis et al (1980) や Deluga（1998a）の結果によれば，交換 性は高い頻度で結託性は低い頻度で用いられるのに対し て, 看護組織を対象にした㴊上（1992a）や教育組織を対 象にした Chacko（1990）によれば，交換性の頻度は低 く, 結託性の頻度が高かった。この原因の一つには二つ の影響戦略が有効だと思われる組織状況とそうでない状 況があるかもしれない。

以上のように，交換性と結託性に関しては一貫した結 果が得られていないが, 残り四つの影響戦略に関しては 一貫した結果結果が見い出されている。

仮説 2 下位者は上位者に対して合理性を最もよく用 い, 迎合性を中程度用いるが, 主張性やより高い権威性 をあまり用いないであろう。

次に下位者は一つの影響戦略をいつも用いるとは限ら ない。彼らが上位者に影響を及ほす際に，一つの影響戦略 に固執する場合もあれば，様々な影響戦略を組み合わせ 
ながら用いることも明らかになっている (Case, Dosier, Murkison \& Keys, 1988: Falbe \& Yukl, 1992: Yukl, Falbe \& Youn, 1993)。また最初失敗すれば, 彼らは次に 別の影響戦略を用いることも明らかにされている (Deluga, 1988ab: Yukl, falbe \& Youn, 1993)。さらに下位者の 用いる影響戦略の組合わせは, 合理性を中心になされる ことも見い出されている (Falbe \& Yukl, 1992：Yukl, Falbe \& Youn, 1993)。

したがって, 下位者が成功のために繰り返し活発に働 きかけようとすれば, 合理性を中心として様々な影響戦 略を用いるものと思われる。

仮説 3 下位者は成功のために, 上位者に繰り返し何 度も影響を及ぼそうとするほど，合理性を中心として様久 な影響戦略を用いるであろう。

\section{2. 下位者の個人的特徵}

次に下位者の個人的特徴はどのような効果を持つのだ ろうか。まず下位者の性別を検討した結果をみてみる。 Offerman \& Schrier (1985) や Offerman \& Kearney （1988）は女性の下位者が男性の下位者より個人的，依 存的な影響戦略や交涉的戦略をよく用いることを見い出 している。ところが性別の効果がみられなかった研究も あって (Kipnis et al 1980: Steffen \& Eagly, 1985) , 一 貫した結果は得られていない。

次に下位者の社会的なモチベーションや性格と影響戦 略の関連を検討した研究もある。高いパワーモチベーショ ン (Mowday, 1978: Schilit, 1984) や達成モチベーショ ンの下位者 (Schilit, 1984: Chacko, 1990) はそうでない 者に比べて，上位者へ影響を及ほす頻度が高かった。

また自信の高い下位者 (Mowday, 1979) や内部統制 型（Schilit, 1984）及びセルフモニタリングの高い下位者 （Deluga, 1991a）も上位者へ影響を及ほす頻度が高かっ た。以上の結果から，自分に自信があり強い意欲を持ち ながら他者に影響を及ぼそうとする者ほど実際の影響頻 度が高いことが窥える。

仮説 4 自分に自信があり強い意欲を持ちながら, 他 者に影響を及济そうとする下位者ほど上位者への影響頻 度が高まるだろう。

\section{3. 上位者の行動}

階層構造内での社会的影響過程を上位者と下位者の相 互作用プロセスと捉えると，下位者の上方向への影響戦 略に直接大きな影響を及ぼす要因の一つに上位者の行動 が上げられる。これまでの先行研究でも上位者の行動を 下位者に対するリーダーシップとして捉えて, 下位者の 影響戦略にどのような効果を持つのかを検討している。 まず Ansari \& Kapoor（1986）と Blase（1989）は,
上位者のリーダーシップを権威型（下位者に対して権威 的で, 何事も上位者個人で決定する）と参加型（下位者に 配慮的で，何事も話し合って決定する）に分類して検討 している。それによると，下位者は迎合を権威的なリー ダーシップを発揮する上位者に対して多く用い，合理性 を参加的なりーダーシップをとる上位者へ使っていた。㴊 上 (1992a）も，迎合は権威的なリーダーシップを発揮す る上位者に対して，合理性は民主的なリーダーシップを とる上位者へ多く用いられることを明らかにしている。

上位者の構造づくりと配慮行動に関する検討も行われ ている (Chenge, 1983: Deluga, 1988a, 90a: Chacko, 1990）。それによれば，下位者は主張性やより高い権威 性を放任型（構造づくりと配慮がともに低い）の上位者 へ多く用いること，また上位者の構造づくり行動が強ま るほど彼らは合理性とともに, 交換性や結託性などより 戦略的な影響戦略を用いる傾向にあることが一貫して見 い出されている。

さらに最近注目されている変革型リーダーシップとの 関連で, 交換型よりも変革型りーダーシップをとる上位 者に対して，下位者は影響戦略を多く使い，とりわけ合 理性と迎合を中心とした印象操作的な影響戦略を用いる ことが見い出されている（Deluga, 1988b, 90a）。

仮説 5 下位者は合理性を, 配慮的で何事も話し合つ て決定する上位者に対してよく用いるだろう。ただし上 位者の構造づくり行動が強まるほど, 下位者は合理性と ともに交換性や結託性などより戦略的な影響戦略を用い る傾向にあるだろう。

仮説 6 下位者は迎合性を中心とした印象操作を権威 的で，何事も自分自身で決定しょうとする上位者に対し てよく用いるだろう。

仮説 7 下位者は主張性やより高い権威性をほとんど 指示を与えない放任型の上位者に対して，よく用いるだ ろう。

\section{4. 下位者の持つ目標}

一般に意図的な社会的影響過程では，まず影響者側にお いて被影響者にどのような行動や態度を要求するかという 影響者の目標が設定される（古川, 1988; 今井, 1990)。 したがって影響者の設定する目標は, その後の影響戦略 の選択に大きな影響を及浑す。先行研究も下位者の目標 を私的・個人的目標（上位者隹認めてもらう，昇進や昇給 を求めるなど）と公的・組織目標（組織全体のことを考 慮するなど）の二つに分けて検討している (Schmidt \& Kipnis, 1984: Ansari \& Kapoor, 1986: 㴊上, 1992b)。 それによると，合理性は下位者が公的な目標遂行のため に, 迎合性は私的目標遂行に多く用いられることが明ら 
かになっている。ただこの迎合を中心とした印象操作が 実際に上位者へ有効性をもつか否かは極めて難しい。と いうのは，下位者の迎合の個人的な意図を上位者に悟ら れたり，上位者による疑いをかけられたりする危険性が 常に伴うからである（Jones, 1965）。したがって下位者 は迎合によって得られるものとそのような危険性を考慮 した上で判断するものと思われる。

仮説 8 合理性は下位者の公的な目標遂行のために, 迎 合性は私的目標遂行によく用いられるだろう。

\section{5. 状況的要因}

下位者の影響戦略は上位者だけでなく, 他の組織メン バーにも少なからず影響を及脑す。したがって下位者の 行動には様々な状況変数が影響力をもつと思われる。と ころが従来の研究は，下位者自身の要因や彼らの直接の 上位者との関係のみに注目して，他の集団変数を取り扱つ ていない。わずかに渕上（1992a）が下位者の所属する集 団の凝集性の効果を検討している。それによれば，下位 者は結託性を彼らの所属する集団の凝集性の高い場合に よく用いていた。

仮説 9 下位者は結託性を彼らの所属する集団の凝集 性の低い場合よりも高い場合に，よく用いるだろう。

\section{IV. 影響戦略の及ほす効果に関する研究}

さて下位者が様々な要因を考慮しながら，上位者へ働 きかけた後にどのような変化が生じるのだろうか。例え ば Case et al (1988) は, 下位者の影響戦略がその後の 彼ら自身の昇進や評価だけでなく, 上位者との関係や組 織全体の生産性やモラールなど様々な側面に効果を持ち うることを示唆している。この影響戦略の効果は, 上方 向への影響戦略研究の中でも最近注目されてきた領域で ある。ここでは低地位者の影響戦略の及涩寸効果を整理 する。まず下位者の影響戦略の成功・失敗がどのような 効果を及ぼすのかをみていく。次に影響戦略の有効性を 下位者自身の観点から次に上位者と組織全体の観点から 検討する。

\section{1. 下位者の影響戦略の成功・失敗が及ぼす効果}

下位者の影響戦略の成功・失敗はいかなる効果をもたら すのだろうか。下位者の影響戦略の成功を上位者も下位 者自身も共通して影響戦略内容の妥当性や使用方法の適 切性, 他者の支持, 上位者との人間関係などに帰属して いた (Shilit \& Locke, 1982: Case et al, 1988)。さらに 合理性の成功は影響戦略の使用方法の適切さや下位者自 身の有能さに, 迎合性の成功は上司との好ましい対人関 係の結果に帰属されていた (Tandon, Ansari \& Kapoor,
1991）。ところが影響戦略失敗の帰属には上位者と下位 者間で大きな食い違いがみられた。上位者は下位者の影 響戦略の失敗を影響戦略の内容や使用方法の不適切性に 䚻属するのに対して, 下位者は上位者の心の狭さに帰属 する傾向があった（Shilit \& Locke, 1982）。いずれにし ても, 下位者の影響戦略の成功は組織内でのその後の彼 らの発言力を高めることになる (Case et al, 1988)。

仮説10 下位者による影響戦略の成功の帰属は, 上位 者と下位者間で一致するだろう。

仮説11 影響戦略の失敗の帰属は上位者と下位者の間 で食い違いが見られるだろう。

\section{2、下位者の影響戦略が下位者自身に及ぼす効果}

一般に合理性の影響戦略は上位者に最も影響力をもち， 下位者自身の職務満足度や組織へのコミットメントを高 めること, 逆により高い権威性や主張性は上位者へあま り影響力を持たず満足度や組織へのコミットメントを低 下させることが一貫して明らかにされている (Deluga, 1991ab: 㴊上, 1992a: Mowday, 1978: Yukl \& Tracey, 1992: Falbe \& Yukl, 1992）。また迎合は中程度の影響 力をもつものの, より長期的な影響力をもつことや組織全 体の有効性よりも上位者との個人的な関係を維持する際 に有効であることが示唆されている（㴊上, 1992a: Yuk1 \& Tracey, 1992)。

仮説12 下位者の合理性の影響戦略は上位者に最も影 響力をもち，下位者自身の有効性の認知も高いだろう。

仮説13 より高い権威性や主張性は上位者への影響力 が最も弱く, 下位者自身の有効性の認知も低いだろう。

\section{3. 下位者の影響戦略が上位者の認知に及ぼす効果}

次に下位者の影響戦略が上位者の認知にどのような効 果を持つのかみてみる。もともと下位者の印象操作（迎 合, 謝罪, 弁解) が上位者の認知や行動に影響を持つこと は実験研究で明らかにされていた (Kipnis \& Vaderveer, 1971: Fodor, 1974: Wood \& Mitchell, 1981)。最近に なって印象操作だけでなく, 様々な影響戦略が一定の効 果を持つことが徐々に報告されている。例えば下位者に よる合理性の影響戦略は, 上位者の内面的納得を高める こと, 逆により高い権威性や主張性は上位者へあまり影 響力を持たず反発や抵抗を招くことが明らかにされてい る (Yukl \& Tracey, 1992: Falbe \& Yukl, 1992)。また Kipnis \& Schmidt (1988) と Deluga（1991a）は主張性 やより高い権威性及び交換性を頻繁に用いる下位者に対 して，上位者は高いストレスを認知することを見い出し ている。

さらに Kipnis \& Schmidt（1988）はこのような下位者 に対する上位者の評価は低く，給与も低いこと，逆に合 
理性を用いる低位者に対する上位者の評価や給与は高い ことを明らかにしている。

仮説14 合理性を用いる低位者へ上位者は肯定的な認 知や好意的な行動を示し，上位者自身の認知するストレ スも低いだろう。

仮説15 主張性やより高い権威性を用いる低位者へ上 位者は否定的な認知や非好意的な行動を示し, 上位者自 身の認知するストレスも高いだろう。

\section{V. 今後の研究展開}

最後に今後の研究展開のために欠かせない問題点につ いて整理する。

まず第一にこれまで明らかになった下位者の影響戦略 を規定する複数の要因の重みづけを行う必要がある。従 来の研究によって, 下位者の影響戦略の選択に影響を及 ぽすいくつかの重要な要因（個人特徴, 上位者のリーダー 行動, 目標, 状況的要因) が検討されてきた。ところが それらの中でどの要因が最も影響力を持つかはほとんど わかっていない。この点を明らかにしない限り, 下位者 の各影響戦略の発生メカニズムがより明瞭な形で説明で きない。今後多変量解析等を用いながら,この点を明ら かにする必要がある。

次に従来の研究はどちらかと言えば, 将来の上位者の 認知・反応やそれを受けての下位者の認知や行動に集中 して, 両者の過去の相互作用の歴史をほとんど考慮して いない。ところがこれまで繰り返し指摘してきたように， 下位者の影響戦略は上位者との相互影響過程の一つであ り, そこでは突如相互作用を始めたのではなく, それに 至るまでの過去の歴史がある。そしてその過去の歴史が 下位者の影響戦略の選択にも多大な影響を及涩している 可能性がある（㴊上, 1993）。したがって, 今後は過去と 将来の視点を加えた研究を進めていく必要がある。その ためには継続的な相互作用のデー夕を収集しながら, そ れらの時系列的な変化を検討していくことも重要になっ てくる。これらの方法は一度に数多くの研究対象を設定 できない。統制できない不測の外的影響要因が存在する 場合があるなど様久な研究方法の限界があるものの, よ り現実性の高い上位者と下位者の相互作用プロセスと組 織の有効性に関する研究成果を期待できよう。

第三に, 下位者の影響戦略が両者の関係だけでなく, 組 織全体にどのような影響を及ぼすのかを検討する必要が ある。より広い視野から下位者の影響戦略の効果を検討 することは組織の有効性や発達及び組織の変革に関する 研究と密接に関連する。
最後に一から三までの問題点を含めた上でのより精緻 な相互作用プロセスモデルを構築していく必要があるだ ろう。このモデルは下位者の影響戦略だけでなく, 上位 者と下位者の相互影響過程も含めたより幅広い社会的影 響過程研究の枠組みを提供できる。ただここでのプロセ スモデルは, 一般的な社会的影響過程におけるプロセス モデル（例えば Ravan, 1992：今井, 1993）とやや異な り，より具体化された状況の中で設定されるべきである。 なぜなら下位者の上方向への影響戦略行動は極めて意図 的・戦略的なものであるから, 各影響戦略が有効な状況 と有効でない状況を特定化した上でモデル化を進める必 要がある。したがって, 下位者の影響戦略が有効である と思われるより具体的な意思決定状況で, 彼らの認知過 程を中心とした上位者との相互作用プロセスモデルを構 築していく必要があろう。

\section{引用文献}

Ansari, M. A., \& Kapoor, A. 1986 Organizational context and upward influence tactics. Organizational Behavior \& Human Decision Prosesses, 40, $39-49$.

Anderson, L. R., Tolson, J. Field, M. W. \& Thacker, J. 1990 Extension of the pelz effect: The impact of Leaders' upward influence on group members' control within the organization. Basic \& Applied Social Psychology, 11, 19-32.

Anderson, L. R. \& Tolson, J. 1991 Leaders' upward influence in the organization: Replication and extension of hte pelz effect to include group support and self-monitoring. Small Group Research, 22, 59-75.

Bass, B. 1990 Bass \& Stogdill's Handbook of Leadership. New York : Free Press.

Bacharach, S. B. \& Lawler, E. J. 1980 Power and Politics in Organizations. San Francisco : JosseyBass.

Barnett, B. G. 1984 Subordinate teacher power in school organizations. Sociology of Education, 57, 43-55.

Blase, J. 1989 The micropolitics of the school: The everyday political orientation of teachers towards open school principals. Educational Administration Quarterly, 25, 377-407.

Blase, J. (Ed.) 1991 The Politics of Life in Schools- 
power, conflict, and cooperation. Newbury Park: Sage Publications.

Case, T., Doiser, L., Murkison, G. \& Keys, B. 1988 How managers influence superiors: a study of upward influence tactics. Leadership and Organizational Development Journal, 9, 25-31.

Chacko, H. 1990 Methods of upward influence, motivational needs, and administrators' perceptions of their supervisors' leadership styles. Group \& Organizational Studies, 15, 253-265.

Cheng, J. L. 1983 Organizational context and upward influence: An experimental study of the use of power tactics. Group \& Organizational Studies, 8, 337-355.

Cohen, A. 1958 Upward communication in experimentally created hierarchies. Human Relation, 11, $41-53$.

Deluga, R. 1988a Relationship of transformational and transactional leadership with employee influencing strtegies. Group \& Organization Studies, 13, 456-467.

Deluga, R. 1988b The Politics of leadership: The relationship between task-people leadership and subordinate influence strategies. Journal of Organizational Behavior, 9, 359-366.

Deluga, R. 1990 The effects of transformational, Transactional and laissez faire leadership characteristics on subordinate influencing behavior. Basic \& Applied Social Psychology, 11, 191-203.

Deluga, R. 1991a The relationship of subordinate influence behavior, healthcare manager, interpersonal stress and performance. Journal of Applied Social Psychology, 21, 78-88.

Deluga, R. 1991b The relationship of upward influence behavior with subordinate-impression management characteristics. Journal of Applied Social Psychology, 21, 1145-1160.

Droy, A. \& Romm, T. 1990 The definition of organizational politics: a review. Human Relations, 43, 1133-1154.

Eresz, M., Rim, Y. \& Keider, I. 1986 The two sides of the tactics of influence. Journal of Occupational Psychology, 59, 25-39.

Falbe, C. M. \& Yukl, G. 1992 Cosequences for managers of influence tactics and combinations of tactics. Academy of Management Journal, 35, 638-652.

Fodor, E. M. 1974 Disparagement by a subordinate as an influence on the use of power. Journal of Applied Psychology, 59, 652-655.

French, J. R. P., Jr. \& Raven, B. H. 1959 The bases of social power. In D. Cartwright (Ed.) Studies in Social Power. Michigan: Institute for Social Research. (三隅二不二・佐々木薰（編訳）1970 グ ループダイナミックス II 社会的勢力 727-748. 誠信 書房)

㴊上克義 $1992 \mathrm{a}$ 部下の影響戦略・部下とリーダーの 関係性に及ぼすリーダー行動の効果心理学研究，63, 107-113.

㴊上克義 $1992 b$ 組織の有効性と部下の影響戦略の関 係 日本心理学会第 56 回大会発表論文集, 246 .

㴊上克義 1993 過去の相互作用がフォロワーの影響戦 略に及ぼす効果 日本グループ・ダイナミックス学 会 第 41 回大会発表論文集, 134-135.

古川久敬 1988 組織デザイン論一社会心理学的アプ ローチ 誠信書房

古川久敬 1992 リーダー行動研究の新しいフレイミン グ 九州大学教育学部紀要（教育心理学部門） 36 , 13-35.

Giacalone, D. C. \& Rosenfeld, P. 1989 Impression Management in Organizations. Hillsdale, NJ: Erlbaum.

Graen, G. 1976 Role making processes within complex organizations. In M. D. Dunnette (Ed.), Handbook of Industrial and Organizational Psychology. Chicago: Rand McNally.

Hinkin, T. R. \& Schriesheim, C. A. 1989 Development and application of new scales to measure the French and Raven (1959) bases of social power. Journal of Applied Psychology, 74, 561-567.

Hoyle, E. 1986 The Politics of School Management. London: Hodder and Stoughton.

今井芳昭 1990 第 1 章 社会的勢力 10-19 大坊郁夫 安藤清志・池田謙一（編集）社会心理学パースペク ティブ第 3 巻一集団から社会へ 誠信書房

今井芳昭 1992 社会的影響過程における社会的勢力認 知機能 東京大学大学院社会学研究科博士論文要旨 (未刊)

今井芳昭 1993 社会的勢力に関連する研究の流れ: 尺 度化, 影響手段, 勢力動機, 勢力変性効果, そして 
社会的影響モデル 流通経済大学社会学部論集, 3 , 39-66.

Jones, E. E. 1964 Ingratiation. New York: AppletonCentury-Crofts.

金井壽宏 1991 変革型ミドルの探求一戦略・革新志向 の管理者行動一 白桃書房

Kelly, H. H. 1951 Communication in experimentally created hierarchies. Human Relations, 4, 39-56.

Kipnis, D., 1990 Technology and Power. New York: Springer-Verlag.

Kipnis, D., Schmidt, S. M. \& Wilkinson, I. 1980 Intraorganizational influence tactics: Explorations in getting one's way. Journal of Applied Psychology, 65, 440-452.

Kipnis, D., \& Schmidt, S. M. 1988 Upward influence styles: Relationship with performance evaluations, salary, and stress. Administrative Science Quarterly, 33, 528-542.

Kipnis, D. \& Vanderveer, R. 1971 Ingratiation and the use of power. Journal of Personality \& Social Psychology, 35, 537-547.

Kumar, K. \& Beyerlein, M. 1991 Construction and validation of instrument for measuring ingratiatory behaviors in organizational settings. Journal of Applied Psychology, 76, 619-627.

Liden, R. C., \& Mitchell, T. R. 1988 Ingratiatory behavior in organizational setting. Academy of Management Review, 13, 572-587.

Lord, R. G. \& Maher, K. J. 1991 Leadership and Information Processing - Linking perceptions and performance. Boston Unwin : Harper Collins.

Madison, D. L., Allen, R. W., Porter, L. W., Renwick, P. A. \& Mayes, B. T. 1980 Organizational Politics: An exploration of managers' perception. Human Relations, 33, 79-100.

Mayes, B. T. \& Allen, R. W. 1977 Toward a definition of organizational politics. Academy of Management Review, 2, 672-678.

Mitchell, T. R., Green, S. G., \& Wood, R. E. 1981 An attributional model of leadership and the poor performing subordinate: Development and validation. In B. M. Staw and L. L. Cummings (Eds.), Research in Organizational Behavior. 3, 197-234. Greenwich, CT: JAI Press.
Mowday, R. T. 1978 The exercise of upward influence in organizations. Administrative Science Quarterly, 23, 137-156.

Mowday, R. T. 1979 Leader characteristics, selfconfidence, and methods of upward influence in organizational decision situations. Academy of Management Journal, 22, 709-725.

Offerman, L. R. \& Schrier, P. E. 1985 Social influence strategies: The impact of sex, role, and attitude toward power. Personality \& Social Psychology Bulletin, 11, 286-300.

Offerman, L. R. \& Kearney, C. T. 1988 Supervisor sex and subordinate influence strategies. Personality \& Social Psychology Bulletin, 14, 360-367.

Pelz, D. C. 1951 Leadership within a hierachical organization. Journal of Social Issues, 7, 49-55.

Podsakoff, P. M. 1982 Determinants of a supervisor's use of rewards and punishments : a literature review and suggestions for further research. Organizational Behavior \& Human Performance, 29, 58-83.

Raven, B. H. 1992 A power/interaction model of interpersonal influence: French and Raven theory thirty years later. Journal of Social Behavior and Personality, 7, 217-244.

Ralston, D. A. 1985 Employee ingratiation: the role of management. Academy of Management Review, 10, 477-487.

Rahim, M. A. 1988 The development of a leader power inventory. Multivaliate Behavioral Research, 23, 491-503.

Schilit, W. K., \& Locke, E. A. 1982 A study of upward influence in organizations. Administrative Science Quarterly, 27, 304-316.

Schilit, W. K. 1984 An examination of individual differences ad moderators of upward influence activity in strategic decisions. Human Relations, 39, 933-953.

Schmidt, S. M. \& Kipnis, D. 1984 Manager's pursuit of individual and organizational goal, $\mathrm{Hu}$ man Relations, 37, 781-794.

Schriesheim, C. A. \& Hinkin, T. R. 1990 Inflence tactics used by subordinate : a theoretical and empirical analysis and refinement of the Kipnis, Schmidt, Wilkinson subscale, Journal of Applied 
Psychology, 75, 246-257.

Schriesheim, C. A., Hinkin, T. R. \& Podsakoff, P. M. 1990 Canipsative and single-item measures produce erronous results in field studies of French and Raven's (1959) five bases of power? An emprical investigation. Journal of Applied Psychology, 76, 106-114.

Sims, H. P. 1977 The leader as manager of reinforcement contingencies: An empirical example and a model. In J. G. Hunt and L. L. Larson (Eds.), Leadership: The cutting edge. Carbondale: Southern Illinois University Press.

Steffen, V. J. \& Eagly, A. H. 1985 Implicit theories about influence style: the effects of status and sex. Personality \& Social Psychology Bulletin, 11, 191-205.

Tandon, K. Ansari, M. A., \& Kapoor, A. 1991 Attributing upward influence attempts in organizations. Journal of Psychology, 125, 59-63.

Tedeschi, J. \& Melburge, V. 1984 Impression management and influence in the organization. Research in the Sociology of Organizations. 3, 31-58. Greenwich, CT: JAI Press.
Vredenburgh, D. J. \& Maurer, J. G. 1984 A process framework of organizational politics. Human Relations, 37, 47-66.

Wood, R. E., \& Mitchell, T. R. 1981 Manager behavior in social context : the impact of impression management on attribution and disciplinary actions. Organizational Behavior \& Human Performance, -bf 28, 356-378.

Yukl, G. A. 1989 Leadership in Organizations. Englewood Cliffs, NJ : Pretice-Hall.

Yukl, G. A. \& Falbe, C. M. 1990 Influence tactics and objective in upward, downward, and lateral influence attempts. Journal of Applied Psychology, -bf 75, 132-140.

Yukl, G. A., Falbe, C. M. \& Youn, J. Y. 1993 Patterns of influence behavior for managers. Group \& Organization Management, 18, 5-28.

Yukl, G. A. \& Tracey, B. 1992 Consequence of influence tactics used with subordinates, peers, and the boss. Journal of Applied Psychology, 77, 525535 .

$\left(\begin{array}{c}1993 \text { 年 } 2 \text { 月 } 4 \text { 日受稿 } \\ \text { 1993年 } 5 \text { 月 } 15 \text { 日受理 }\end{array}\right)$ 